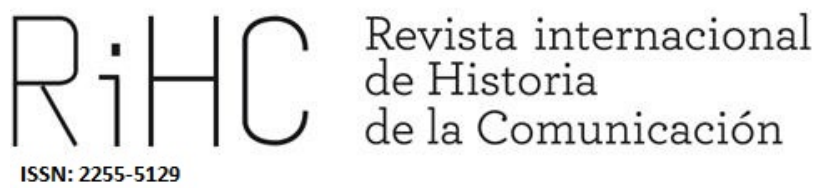

\title{
APORTES SOBRE LA PRENSA PERIÓDICA DE LOS INMIGRANTES ESPAÑOLES EN CHILE
}

Contributions on the periodical press of Spanish immigrants in Chile ${ }^{1}$

DOI: http://dx.doi.org/10.12795/RiHC.2019.i12.10

Recibido: 26/03/2019

Aceptado: 14/05/2019

Publicado:15/06/2019

Marcelo Garabedian

Universidad de Buenos Aires, Argentina

marcelogarabedian@yahoo.com

ORCID (iD) 0000-0001-8106-031X

\footnotetext{
${ }^{1}$ Este artículo forma parte del proyecto “La prensa de la emigración española: Acción cultural, patriotismo y recreación identitaria. Estudios de caso en Argentina, Cuba, México y Uruguay, 1870-1960”. Entidad financiadora: Ministerio de Economía y Competitividad, Plan Nacional I+D, HAR2015-64494-R
}

Como citar este artículo: GARABEDIAN, Marcelo (2019): "Aportes sobre la prensa periódica de los inmigrantes españoles en Chile", en Revista Internacional de Historia de la Comunicación, (12) ISSN 22555129, pp. 201-221. 
Resumen: En comparación con la región rioplatense y con Cuba, las repúblicas del Pacífico no se destacaron como destinos preferidos por los emigrantes españoles durante la época de la gran inmigración (1850 - 1930). El caso particular chileno tampoco mostró volúmenes muy importantes con alrededor de veinte mil españoles hacia 1900. Si bien existen muy buenos trabajos sobre la migración española a Chile, el estudio de su prensa ha quedado relegada. Dentro del conjunto de diarios y periódicos que los inmigrantes emprendieron en ciudades como Santiago y Valparaíso, se analizarán algunas experiencias como el periódico La voz de España, dirigido por el escritor Genaro Cavestany y el mensuario España y Chile dirigido por Luis Moncayo y Telmo Arena.

Palabras clave: inmigración española, prensa, identidades nacionales, Chile.

\begin{abstract}
In comparison with the River Plate region and Cuba, the Pacific republics did not stand out as preferred destinations for Spanish emigrants during the time of the great immigration (1850 - 1930). The Chilean particular case also did not show very important volumes with around twenty thousand Spaniards around 1900. Although there are very good works on the Spanish migration to Chile, the study of its press has been relegated. Within the set of newspapers that immigrants undertook in cities such as Santiago and Valparaíso, some experiences will be analyzed, such as the newspaper La voz de España, directed by the writer Genaro Cavestany and the monthly magazine España y Chile directed by Luis Moncayo and Telmo Arena.
\end{abstract}

Keywords: Spaniard immigration, press, national identities, Chile.

\title{
Introducción
}

La inmigración española en Chile mantuvo volúmenes modestos si se lo compara con las repúblicas del Río de la Plata, pero puede mostrar cifras homogéneas al grueso de las repúblicas americanas del Pacífico durante todo el siglo XIX. EI Censo General de 1854 contabilizó 781 españoles, 1822 alemanes, 1663 ingleses y 1650 franceses (Censo General, 1858: 152). Hacia comienzos del siglo XX residían alrededor de diez mil españoles en el país, convirtiéndose en el grupo europeo más numeroso. Para el año 1920, los inmigrantes españoles explicaban el 35.9\% del total de los europeos residentes en Chile con veinte y seis mil personas (Estrada Turra, 2012: 258).

Para adquirir una dimensión aproximada del peso de la población española en las ciudades de Valparaíso y Santiago, podemos indicar que para 1895 la ciudad puerto contabilizaba 1.317 peninsulares sobre un total de 10.300 extranjeros, mientras que la capital en ese mismo año albergaba a 2688 españoles sobre un conjunto de extranjeros que se acercaba a las 11.600 personas. Valparaíso según los censos tenía una población de 122.447 habitantes. Santiago de Chile para el año 1907 contaba con una población 
total de 256.403 habitantes, de los cuales 6565 inmigrantes eran de origen español (Estrada Turra, 2018: 62).

La participación del colectivo español en la trama productiva económica chilena estuvo mayoritariamente concentrada en el sector terciario y también como propietarios de pequeñas y medianas industrias. Los rubros en donde se destacaron los inmigrantes estuvieron orientados sobre todo a partir de las redes y cadenas migratorias en cada sociedad de destino. Así fue cómo en Valparaíso y Santiago los inmigrantes asturianos priorizaron el rubro de la ferretería y la mercería, los catalanes la vitivinicultura y la molinera, los riojanos se orientaron hacia el rubro del calzado, los gallegos en el área gastronómica y la panadería, y los vascos, que en la Argentina se destacaron sobre todo por su actividad en la lechería, en Chile se orientaron mayoritariamente al negocio de la curtiembre. El flujo regional mayoritario que se estableció en Chile provino de la región norteña de Asturias, seguido por los vascos y los catalanes, en ese orden (Estrada Turra, 2018: 107).

La ciudad de Valparaíso y la capital chilena acapararon el grueso de esta inmigración peninsular y allí se establecieron las instituciones más importantes de la colectividad. Podríamos afirmar que en estas dos ciudades se estableció el núcleo de la sociabilidad española en el país. En Santiago de Chile se fundaron el Círculo Español (1880) y el Centro Español (1895), la Asociación Española de Socorros Mutuos (1875) mientras que en la ciudad portuaria se crearon el Centro Español (1874), la Sociedad española de Socorros Mutuos (1877) y el Banco Español - Italiano (1900) (Estrada Turra, 2012: 60).

El medio de la prensa chilena estuvo dominado por dimensiones acotadas dentro de un contexto de fragilidad financiera de los emprendimientos periodísticos, dado el carácter acotado del campo de lectores circunscriptos en la élite política chilena y de las escasas tiradas diarias de los periódicos. El diario pionero de Valparaíso, nos referimos a El Mercurio, fundado en 1827, poseía según nos relata Barros Arana unos mil ejemplares diarios y en total, según un artículo de Cherniavsky, todos los periódicos editados en Chile para la segunda mitad del siglo XIX no superaban los dos mil quinientos ejemplares (Santa Cruz, 2014: 559 - 560). El primer periódico que se publicó en Santiago de Chile fue La Aurora de Chile en el año 1812, y en la primera mitad del siglo XIX el periódico que sobresalió a sus contemporáneos fue El Araucano (1830 - 1877). Habría que esperar hasta las últimas décadas del siglo XIX para que comenzara a surgir un periodismo informativo sobre un mercado editorial más consolidado y un campo periodístico moderno (Santa Cruz, 2014: 561).

Dentro del contexto anteriormente reseñado, el periodismo español tuvo una presencia importante en el medio chileno. La primera publicación data de 1878 y se registró en Valparaíso a partir del trabajo del periodista español Julio Real y Prado. Haciendo una salvedad para El Noticiero español (1889-1903), el resto de las publicaciones encontradas han tenido una vida efímera, lo que nos ofrece la pauta para pensar en un 
mercado de lectores españoles pequeño y con escaso desarrollo. Entre los periódicos que se publicaron en las ciudades de Valparaíso y Santiago para el último cuarto del siglo XIX podemos nombrar los siguientes: El Eco de España (1877); España y Chile (1886); EI Noticiero Español (1889 - 1903); La España (1897 - 1898); La voz de España (1901)².

En este artículo nos proponemos analizar algunas de las publicaciones que en el cambio de siglo se publicaron en Chile, focalizando especialmente en el periódico La voz de España, fundado y dirigido por Genaro Cavestany y González Nandín (1857 - 1921).

\section{Los pioneros: La voz de España de Genaro Cavestany}

Cavestany nació en Sevilla, fue escritor, periodista y autor de varias novelas, ensayos históricos y autobiografías. En 1878 se graduó como Doctor en Derecho en la Universidad Central de Madrid donde fue compañero y camarada de Leopoldo Alas, "Clarín". En su recorrido por América Latina residió en Cuba, México, Uruguay y Chile. A su regreso a Europa luego del periplo americano fijó residencia en París, trabajando para algunos periódicos parisinos. Mantuvo una relación epistolar con algunas de las célebres figuras del hispanismo de la época como Rubén Darío.

A poco de su llegada a Valparaíso, decidido a fundar allí un periódico, publicó un ejemplar prospecto el 14 de mayo de 1901 de su semanario La voz de España. Existió un estudio por parte del escritor sevillano de las plazas americanas en donde fuera posible la aparición de una "hoja española" en soledad. Las ciudades suramericanas más importantes como Buenos Aires, Montevideo, Rosario y San Pablo, incluyendo también la capital chilena, ya contaban con órganos españoles. En esta línea, la ciudad puerto de Valparaíso carecía por ese entonces de un periódico español. Como lo afirmó el propio Cavestany

es inconcebible cómo el más importante puerto al Pacífico de la América del Sur, ha podido estar tanto tiempo sin un órgano de la Colonia Española, la más importante, si no por el número, sí por su honorabilidad y alta representación en el comercio y en la sociedad ${ }^{3}$.

\footnotetext{
${ }^{2}$ Un trabajo pionero sobre la prensa española en Chile es el de FERNANDEZ PESQUERO, Javier (1919) "Historia de la prensa española en Chile" en AA.VV. España en Chile. El comercio y las industrias en la República de Chile, Santiago.

3 “Hoja prospecto", La voz de España, 14/05/1901.
} 
El antecedente más inmediato de un periódico español en Valparaíso lo había constituido el proyecto periodístico de Felipe Aparicio Sarabia (1867 - 1945) titulado La España. Esta hoja se editó en forma de semanario durante todo el año de 1897 y los primeros meses de 1898 llegando a completar 109 números. El director de esta publicación emigró a Chile en el año 1889 y cumplió la mayor parte de su labor periodística y literaria en ese país, donde se destacó su novela con rasgo autobiográfico Memorias de un roto, publicada en Valparaíso en el año 1899.

La ciudad de Valparaíso no contaba con un diario de la colectividad española al momento de la aparición pública de La España. Creemos que esa coyuntura ameritaba una empresa periodística por tratarse de los años de la Guerra de Cuba, cuando se avizoraba un ingreso formal de los Estados Unidos en la contienda. Entendemos que éstos fueron también los razonamientos de Aparicio Sarabia, quien destinó buena parte de su semanario a informar sobre los sucesos bélicos, a defender la posición de España y su reclamo frente a las islas en la prensa periódica chilena y a exacerbar el sentimiento nacionalista español.

El semanario se esforzó por mantener un discurso de un nacionalismo español que fuera impermeable a las críticas. Esta decisión editorial se puso de manifiesto al no encontrar en la publicación ninguna alusión a las divisiones políticas españolas, evitando por esta vía un alineamiento del mismo semanario a ningún sector político. Al igual que la prensa española de otras latitudes, la hoja de Valparaíso suprimió de sus páginas las referencias a la política doméstica, así como tampoco emitió opinión sobre la política chilena. Otras de las decisiones editoriales para destacar fue la ausencia de tratamiento acerca del separatismo por parte de las provincias del norte, en especial el catalán y el vasco. Entendemos que las dimensiones reducidas del número de españoles en Valparaíso, el momento por el cual transcurrió su duración y el hecho que se tratara de un semanario, hicieron que el espacio de la publicación se destinara a los temas más relevantes de la coyuntura.

Volviendo al análisis del periódico de Cavestany. La Voz de España del año 1901, encontramos que sus objetivos fueron desde la defensa material de los "intereses de los españoles" hasta aquellos considerados "morales". En este punto, se proponía la reivindicación de la tradición española como

contribuir a que nuestro hermoso idioma se conserve en toda su pureza en este territorio, a que se restablezcan las comunicaciones marítimas con nuestra Nación, interrumpidas por el momento, a que nuestros artistas y artes sean honrados y en una palabra a que nuestra Patria sea venerada en este país. ${ }^{4}$

Había una aceptación de las funciones que la prensa de inmigrantes debía ejercer en las sociedades de destino. En este sentido y por la experiencia recogida en otros países, el

\footnotetext{
4 “Hoja prospecto”, La voz de España, 14/05/1901
} 
novel director de la hoja todavía nonata lo sabía bien. Consciente de la hispanofobia de las clases populares y de ciertas miradas despectivas por parte de sectores de la élite hacia la tradición hispánica, recordemos la influencia sarmientina tanto en Chile como en la Argentina, Cavestany dejaba en claro alguna de las misiones más importantes de los periódicos españoles en América.

Por otra parte, otra de las reglas "no escritas" en el juego de la prensa periódica de la época fue la no injerencia de los "extranjeros" en la política local. Si bien nadie podía negar ese derecho, no faltaban las críticas toda vez que se cruzara "ese límite" a la tolerancia de las élites locales. Por este motivo, como era una "norma" en los prospectos de la época afirmaba:

desde el primer momento nos imponemos el deber de no mezclarnos para nada en la política interna del país respetando cuantas leyes se dicten", pero inmediatamente advertía, también siguiendo el canon periodístico del momento que, en cambio, "exigiremos un respeto profundo en sus gobernantes y en sus gobernados no solo para nuestra colonia sino para el nombre de nuestra patria ${ }^{5}$.

Los límites autoimpuestos para las opiniones periodísticas sobre la política local, aunque no siempre se cumplieron, estuvieron explicitados como una de las normas de convivencia a la que nos referimos en el párrafo anterior. Esta conducta no se reprodujo a la hora de verter sus opiniones sobre la marcha de los asuntos públicos en la península. Las posiciones políticas del diario publicado en Valparaíso se expresaron a través de la columna "Las últimas noticias de España". En el primer número del periódico del 19 de mayo de 1901, Cavestany criticó a Sagasta y a su nuevo gobierno, mostrando preferencias por el bloque del conservador Silvela. Juzgó severamente la autonomía administrativa que los liberales pretendían otorgarle a Cataluña y se mostraron partidarios de la asunción del futuro rey Alfonso XIII para que "estabilice" al país. Mientras, por ese entonces, El Correo Español en Buenos Aires comenzaba a agitar las aguas de la República y la revolución, luego del "desastre del 98", La Voz de España publicaba la columna "Revolución y evolución" marcando no sólo su posición y sus preferencias en cuanto al rumbo que debía seguir la política española, sino también poniendo límites a las nuevas corrientes revolucionarias que se agitaban en la península y de las que Cavestany fue un opositor frontal ${ }^{6}$.

El rumbo preferido por el periodista defensor de la monarquía constitucional fue la "evolución". Para él, "la evolución al subjetivarse en la humanidad destruirá la revolución porque es la niveladora social por medio del orden", ya que el carácter progresivo del crecimiento "nivelará" a los distintos sectores de la sociedad. Si bien para Cavestany las diferencias entre las clases sociales era fundamental ya que de ahí surgiría

\footnotetext{
5 “Hoja prospecto”, La voz de España, 14/05/1901.

6 “Revolución y evolución”, La Voz de España, 23/6/1901. P2.
} 
el ordenamiento, esta estructura debería permitir un mejoramiento general, fundamentalmente para evitar la "revolución", que se asemeja "al reactivo obtenido en el laboratorio, rápido pero deleznable" ${ }^{\prime 7}$. El origen de estos desequilibrios vertiginosos fue la "revolución francesa" que demolió los cimientos del "orden" y posibilitó la institución de la República, que daría paso a la anarquía. En esta línea, para el autor de la nota el camino estaba dado por la emergencia de una figura "fuerte" que "ordenara" la sociedad, para que las fuerzas del progreso la nivelaran. En la columna, esta figura estuvo personificado por Napoleón Bonaparte, el "restaurador del orden desquiciado, y así como Jesús redimió al mundo, Napoleón equilibró a la Europa".

La evolución se personificó en la figura de Gutemberg, quien con la imprenta

...ilustró la masa popular y arrancó a los condes y tiranos feudales el monopolio del mando vinculado de antiguo en las familias linajudas y hoy nuestros mandatarios, con excepción de los reyes, no heredan el gobierno popular de sus mayores sino que lo obtienen de sus talentos.

Junto con la necesaria ilustración del pueblo, se incorporó también a la ciencia y a la industria, como elementos necesarios en el camino de la evolución social. La tríada educación, ciencia e industria realizarán la tarea de la transformación armoniosa, bajo el mando de una figura que "equilibre el poder en las naciones" ${ }^{8}$. Volviendo a la realidad finisecular española, un sector importante de las élites políticas razonaba que la figura de la monarquía resultaba necesaria para el ordenamiento político de las facciones, sobre todo luego de la derrota del 98 y teniendo en cuenta la emergencia de los nacionalismos periféricos del norte que amenazaban el horizonte político español.

Esta elección se vio ratificada con la columna "La legación española en la República Argentina". En esa nota Cavestany exigió al representante español en las repúblicas suramericanas que actuara en defensa de la Princesa de Asturias, quien había sido "insultada de la manera más villana a la angelical princesa" y exigiera al gobierno argentino las reparaciones y sanciones correspondientes. El villano en cuestión era Eduardo Sojo y la publicación era la revista Don Quijote. A pesar del reclamo periodístico de Cavestany, el representante diplomático Julio Arellano y Arróspide no interpuso ninguna acción al respecto, creemos nosotros por ser un conocedor del medio periodístico y político bonaerense, en donde las críticas y ridiculizaciones a través de la prensa estaban toleradas y aceptadas.

Cavestany en la misiva aclaró estar dispuesto a reclamar él personalmente por el honor mancillado de los miembros de la realeza española, "estoy dispuesto a exigir reparación de tan villanas ofensas, autorizándome a mí propio para tomar el honroso puesto de

\footnotetext{
7 “Revolución y evolución”, La Voz de España, 23/6/1901. P2.

8 “Revolución y evolución”, La Voz de España, 23/6/1901. P2.
} 
defensor de nuestros reyes" ${ }^{\prime 9}$. Claramente puede observarse los límites políticos de las colonias españolas de Chile y de Argentina. A pesar de que ya existían en el país facciones dentro de la colectividad española enfrentadas públicamente a través de la prensa, no encontramos periodista español alguno que tomara la pluma en el periodismo porteño para la defensa de la Princesa ofendida por Sojo.

Esta actitud del director de La voz de España llamó la atención de la prensa periódica de los italianos en Valparaíso, quienes señalaron que el diario es de "entonación seria, patrióticamente amante de la monarquía e invoca más de lo necesario la protección de la corte celestial sobre la terrenal" ${ }^{10}$.

Un punto no menor fue el estudio y análisis de los márgenes políticos de la sociedad local. Para el caso chileno, durante casi todo el siglo XIX existieron una serie de consensos entre liberales y conservadores. Las investigaciones recientes refuerzan la idea de las coincidencias entre ambas facciones políticas, fundamentalmente sobre la preferencia en el Republicanismo, existiendo matices sobre los niveles de laicidad en la educación y en el ámbito de la religión sobre la sociedad (Gazmuri Stein, 2018: 50). Los límites que las élites políticas locales estaban dispuestos a tolerar, sobre todo de aquellos extranjeros que arribaron para tomar un espacio en la prensa, fue siempre un dato esencial para considerar. Estas coordenadas políticas podían explicar la supervivencia de la misma publicación que se intentara iniciar. Un ejemplo importante fue la experiencia vivida de la hoja española editada en la capital chilena titulada España y Chile.

\section{España y Chile}

El proyecto periodístico iniciado en Santiago de Chile por los españoles Telmo Arenas y Luis Moncayo durante el mes de mayo de 1886 presentó una postura política que rápidamente fue advertida por el medio político y periodístico chileno. Las mismas tuvieron que ver con la posición política republicana, democrática y federal que los redactores y colaboradores del periódico expresaron con respecto al gobierno de España y también la decisión de opinar críticamente sobre algunos temas del ámbito local, cruzando una línea incómoda para la arena periodística chilena.

Una de las columnas que analizaremos a continuación se tituló “Despierta, España, Despierta" y fue firmada por Ricardo Feijóo y Pardiñas, periodista y abogado republicano gallego quien debió exiliarse a Francia en 1873 desde donde siguió defendiendo al ala

\footnotetext{
9 “La legación española en la República Argentina”, La voz de España, 19/05/1901, P1.

10 "Salutaciones a la voz de España”, La voz de España, 26/05/1901, P2.
} 
más radical del sexenio revolucionario en la prensa republicana. Los puntos más salientes del escrito fueron la delimitación de la historia más importante del pasado entendido como nacional. Se rescataron las figuras del republicanismo español del primer cuarto del siglo XIX, desde Padilla y Riego hasta llegar a Prim, como una continuidad del Republicanismo y de lo más genuino de "la tradición liberal española". Esta corriente liberal republicana se integró con la vertiente federal y se transformó en una crítica muy abierta al gobierno de la Restauración y a la Reina Regente María Cristina, luego de la muerte de Alfonso XII en 1885, cercano a las posiciones radicales del también exiliado Manuel Ruiz Zorrilla ${ }^{11}$.

A través del recorrido por el artículo, el autor dejó claras las posiciones políticas criticando la religión y la monarquía y dejando la solución para el pueblo español: "abraza con fe la bandera de la República federal que es la palanca con la cual removerás a esta sociedad vieja, corroída y corrompida por el cáncer del vicio y moribundo escepticismo"12.

Esta fue también la línea que adoptó la columna "Los traidores y la federación", en donde Feijóo y Pardiña delimitó la línea de la Historia española entre los que defendieron y aún defienden la honra española y los "traidores", que se aliaron a los extranjeros (romanos, moros y franceses) y que se encarnaron en la construcción política de la monarquía, primero los Habsburgo y luego los Borbones. Entre las reivindicaciones realizadas figuran el valor del municipio y los fueros, ámbito histórico de la libertad y de la democracia directa del pueblo, como un valor para esta construcción histórica de la identidad nacional española. Esta línea teleológica culminaría con el triunfo de la República afirmando:

...si las leyes históricas se cumplen será una regencia luctuosa de sangre y desdichas, porque habrá la más cruel de las guerras civiles, lucha sin cuartel entre la monarquía y la República. El triunfo será de la democracia, porque así lo exige el pueblo español, que lo espera todo de las circunstancias. iLos traidores! Aún hoy existen. Pero la federación los hará desaparecer para siempre de la tierra del honor, del valor, la libertad y la caballerosidad ${ }^{13}$.

Estas definiciones de posicionamiento político se complementaron con las críticas que los redactores de España y Chile al sistema de crédito chileno y a la higiene pública de Santiago, por tomar sólo dos escritos salientes y también con las caricaturas sobre la Virgen María y otros personajes ${ }^{14}$. Estas columnas no pasaron desapercibidas en el medio chileno y en el tercer número debió salir a dar explicaciones sobre sus escritos.

\footnotetext{
${ }^{11}$ ¡Despierta España, despierta!, España y Chile, 21/5/1886. P1

12 ¡Despierta España, despierta!, España y Chile, 21/5/1886. P1

13 "Los traidores y la federación", España y Chile, 30/6/1886. P2

${ }^{14}$ Al respecto ver: “El Crédito” y “iEsa higiene!”, España y Chile, 30/06/1886. P1
} 
En la nota "Una crítica inmerecida", del 16 de julio de 1886, Luis Moncayo se preguntaba ofuscado:

¿de cuándo acá un extranjero que se establece en Chile no puede mezclarse en la política interna de este país sin cometer un crimen? Parece que en esta tierra se olvida que los primeros y mejores diaristas que fundaron el periodismo en Chile han sido casi todos extranjeros ${ }^{15}$.

Los diarios nacionales como La libertad electoral y Los debates, ambos publicados en Santiago, observaron las columnas del nobel mensuario español y le auguraron un futuro sombrío si continuaba con esa línea editorial. Al respecto La libertad electoral afirmaba:

Hemos examinado con detenimiento esa hoja que trae una caricatura iluminada de una desagraciada concepción y de poquísima gracia y nos hemos cerciorado que si España y Chile sigue saliendo como ha salido su número prospecto y su número extraordinario el público sensato y discreto le negará su favorable acogida y lo mirará con la indiferencia más profunda. Si España y Chile quiere hacer fortunas debe cambiar de rumbo y sobre todo no meterse en camisa de once $\operatorname{varas}^{16}$.

La respuesta del director del diario español no se hizo esperar afirmando que era un deber de republicano informar a sus lectores sobre las cuestiones salientes de la realidad y que estaban amparados por la Constitución chilena: "triste cosa sería entonces mantener a nuestros lectores privados de la cosa pública, si debieran los otros diarios ponernos candados en la boca, como hicieron los gentiles con un santo predicador". ${ }^{17}$

Tomando estas críticas de los diarios como un indicio, creemos que el reducido grupo de inmigrantes españoles de Santiago y sus élites no le dieron su apoyo a la incipiente publicación. Entendemos que los límites políticos chilenos no aceptaban la aparición de publicaciones que auspiciaran en sus columnas una República democrática que corriera los márgenes de la participación genuina e incluyente, y sobre todo con una postura tan radical y revolucionaria. Jaksic afirmaba que había un consenso entre liberales y conservadores que estuvo basado en garantizar la "estabilidad política" del gobierno, aún por sobre la libertad de los ciudadanos, hecho que estuvo expresado en la Constitución de 1833 (Jaksic, 2018: 33). Estos elementos nos ayudan a entender por qué la experiencia periodística de España y Chile no llegara a alcanzar los cuatro ejemplares (Montenegro, 2018: 5).

\footnotetext{
15 “Una crítica inmerecida”, España y Chile, 16/07/1886. P1

16 "La libertad electoral” y “Los debates”, España y Chile, 16/07/1886. P2

17 “Una crítica inmerecida”, España y Chile, 16/7/1886. P1.
} 


\section{La disputa por "mercado de lectores españoles"}

La disputa por los espacios para la prensa en el seno de las colonias de emigrantes fue una constante en todas las sociedades de destino. Podemos encontrarlas con distintos matices en varias plazas americanas. Tampoco fue una excepción en Chile. Ya desde el primer número del 19 de mayo de 1901, volviendo a la experiencia de La voz de España, su director tuvo enfrentamientos con el otro diario que por ese momento se publicaba en Chile, aunque en la ciudad capital. Este periódico titulado El Noticiero Español, fundado y dirigido por Aristarco Rodríguez Menica, había publicado una nota con respecto al cumpleaños del futuro monarca Alfonso XIII, afirmando que, con la mayoría de edad, podría asumir como Rey de España en 1901. Aristarco Rodríguez Menica había nacido en Allariz, Orense, en 1855. Se unió al ejército carlista en 1871 y hasta 1873 y luego se graduó como abogado en 1879 en la Universidad de Valladolid. En 1887 se trasladó a Chile y unos años después fundó su periódico "El Noticiero Español", hasta donde sabemos el diario de mayor duración durante el siglo XIX, desde 1889 hasta 1903.

Aprovechando este error, La voz de España publicó en la primera hoja que el futuro monarca había nacido en 1886 y por lo tanto faltaba un año para su mayoría de edad, lamentando la falta de información del colega, y a la vez competidor, diario español de Santiago ${ }^{18}$.

La "competencia" por "apropiarse" del naciente "mercado de lectores" españoles hizo que, en algunos casos, se llegase a finales trágicos, en pos de evitar el surgimiento de otra publicación que pudiera disputarle ese lugar único. El comentario de Cavestany a su competidor en Santiago de Chile fue elocuente:

...hubiera nacido el señor don Aristarco Rodríguez Menica en la época del génesis del mundo y hubiera estado solo con los animales nacidos antes que él... hubiese sido hecho hombre a mandato del Verbo divino, pero habiendo nacido en el siglo XIX no tiene más remedio que sufrir que haya otro periódico español en Valparaíso $^{19}$.

En este caso puntual entre Cavestany y Rodríguez Menica, suponemos que también pesaron las diferencias ideológicas entre ambos. El primero fue partidario de la monarquía constitucional y adherente a las filas del conservadurismo de Cánovas del Castillo y luego de Silvela, mientras que el director de El Noticiero Español había tomado parte en los ejércitos del carlismo durante los años de la guerra civil de la década de 1870.

\footnotetext{
18 “Cumpleaños real”, La voz de España, 19/05/1901. P1

19 “¿Quién es tu enemigo? El de tu oficio”, La voz de España, 26/05/1901. P2.
} 
El caso exitoso por lo extendido de El Noticiero Español puede explicarse a través de una sumatoria de causalidades específicas de Chile. El periodista y abogado ingresó a Chile en el año 1887 encontrando en el país una intensa disputa alrededor de las leyes de laicidad que quería imponer el estado y la facción liberal de la élite política chilena. En este sentido, Rodríguez Menica encontró una facción católica ultramontana muy sólida, con fuertes lazos de solidaridad con el Vaticano y una prensa local con mucha influencia en la opinión pública de la época (Edwards, 2018: 88).

La filiación política dominante en los miembros de la élite de la reducida colectividad española estuvo hegemonizada por simpatizantes del carlismo, entre los que se destacaron José de Respaldiza, Pedro Nolasco de Embeita e Ignacio de Yturbe y Estefanía, entre otros. Esta fue una de las razones por las cuales la visita del pretendiente Don Carlos a Chile durante el año 1887 fuera experimentado como un verdadero suceso, llegando a visitar al Presidente de la República José Manuel Balmaceda y Fernández el último día de una estadía que duró aproximadamente un mes y estuvo cargada de agasajos y reuniones político partidarias. El Secretario personal de Don Carlos, Francisco Martín Melgar, Conde de Melgar, gozaba de una gran popularidad entre los sectores católicos y conservadores chilenos dado que era un colaborador permanente del periódico ultramontano El Estandarte Católico que se publicaba en la capital chilena (Rivadulla Barrientos, 1992: 277).

Este contexto político nacional de enfrentamiento entre liberales y conservadores católicos, sumado a la hegemonía carlista de buena parte de la élite dirigente de la colonia española en Chile, se sumó al hecho que al momento de la llegada de Rodríguez Menica a Chile, no se publicaba ningún periódico español en la ciudad capital ni en el país. Esta situación favoreció sin duda la continuidad de El Noticiero Español.

El caso puntual de la ciudad de Valparaíso mostraba una realidad particular. La cantidad de españoles en el puerto a principios del siglo XX no dejaron lugar a dudas acerca del limitado número de potenciales lectores de periódicos españoles. Sumado a esto, Valparaíso fue para principios del siglo XX una urbe con poca actividad cultural y con escasos ámbitos para la sociabilidad, realizándose todavía las tertulias en las casas particulares, una práctica que databa de la primera mitad del siglo XIX. Las crónicas de la época describieron a la ciudad puerto como un ámbito con mucha actividad comercial durante el día, pero que por la noche la ausencia de una oferta cultural amplia era notoria. Tímidamente durante la segunda mitad del siglo XX fueron abriéndose espacios destinados a la cultura y al esparcimiento, sobre todo para los miembros de la élite de la región: Club Alemán (1838), Sociedad científica y literaria de Valparaíso (1856), Club Valparaíso (1857), Sociedad amigos de la Ilustración (1859). La elocuencia sobre la anemia de consumos culturales en la ciudad quedó reflejada en los motivos de la creación de la Sociedad de Estudios Científicos y Literarios (1877), quien en sus actas 
fundacionales afirmó que el propósito de su existencia era "aclimatar en nuestro país a esa planta exótica llamada literatura" (Lorenzo, 2012: 25).

Hasta el momento, todos los proyectos periodísticos con que nos hemos encontrado poseían una aparición de dos y hasta tres veces a la semana. Ninguno funcionó como una publicación diaria, incluyendo al periódico de mayor duración para estos años como lo fue El Noticiero español, que se publicó durante catorce años. El resto de los emprendimientos, además de poseer un formato de periódico, tuvieron una duración muy breve. Con estas limitaciones estructurales enumeradas, los pedidos de parte del diario para tener más suscriptores fueron asiduos. Desde La voz de España se apeló a los paisanos para que ayudaran al diario. En la columna "La colonie francaise" se encerraba esta idea sobre la "protección" al diario y de la importancia de la existencia de un diario en las sociedades de destino. Al respecto decía:

los honorables miembros de estas colonias dan al editor de su órgano su decidida protección y han adelantado para la fundación del periódico el abono de un año. Así lo han hecho no sólo en Valparaíso, Santiago, Antofagasta y Concepción sino en otras importantes ciudades de la República. Bien por la actitud de los súbditos franceses, belgas y suizos y ojalá su conducta fuese imitada por los miembros de las demás colonias extranjeras. El mayor número de órganos en la prensa de una colonia favorece altamente el concepto de la ilustración de sus naturales ante los ojos del país extranjero en que viven ${ }^{20}$.

\section{La defensa de España y de la tradición como elemento de identidad nacional}

En Chile, al igual que en el resto de las repúblicas del Pacífico, las corridas de toros fueron un espectáculo que, aunque prohibido legalmente, fue aceptado por parte de la sociedad local. En estas presentaciones se ensalzaba la valentía y el arrojo del 'matador': "Bonarillo estuvo hecho un héroe toda la tarde, con capote, banderillas, muletas y estoque" ${ }^{21}$. Una de las vías de la recreación identitaria estuvo puesta en la reproducción de estas fiestas, muchas veces con la llegada de un "torero" con buen suceso en la península. Esta actividad celebrada en Valparaíso era seguida regularmente por el periódico, quien colocó una sección específica y regular titulada "Toros". Por el

\footnotetext{
20 "La colonie francaise", La voz de España, 2/6/1901. P1

21 “Toros", La voz de España, 2/6/1901 y 16/06/1901, P2
} 
contrario, en las ciudades de Buenos Aires y Rosario, las corridas estuvieron censuradas y no tenían buena acogida por la sociedad local, inhibiendo a los españoles de realizarlas.

La reivindicación de "lo español" se manifestó también desde otros aspectos por parte del diario. Nosotros escogimos algunas de las más características que refuerza nuestra idea sobre cómo fueron delineándose los contornos de la identidad española en América. Al momento de la publicación de La voz de España en Valparaíso se dio la noticia de lo que se juzgó como "un gran avance en la relación entre España y los países americanos". Nos referimos puntualmente a la decisión del Poder Ejecutivo Nacional argentino de retirar del Himno Nacional los párrafos ofensivos y denigratorios hacia España. Esta decisión del gobierno del General Julio Argentino Roca fue recibida con júbilo por la gran colectividad española de la Argentina y fue reflejada desde las páginas del diario de Cavestany como un gran triunfo de España en América.

La columna titulada "La Asociación Patriótica Española de Buenos Aires", publicada el 16 de junio de 1901, dominó gran parte del diario de ese día. Se trataba nada menos que de la decisión del Poder Ejecutivo Nacional argentino de retirar del Himno nacional las estrofas ofensivas dedicadas a España. Luego de agradecer y ensalzar a los miembros de la Junta Directiva y sobre todo a la persona de su Presidente Honorario, al Sr. Gonzalo Segovia y Ardizone, Conde de Casa Segovia, aún por encima del encumbrado, ferviente republicano y verdadero impulsor de la Asociación que fue Rafael Calzada, Cavestany se explayó sobre la institución que impulsó la petición a la modificación del himno argentino. Afirmó que deberían existir más asociaciones de este tipo en América para reforzar los vínculos entre España y sus ex colonias. A través de la red de Asociaciones Patrióticas:

...conseguiríamos destruir la corriente de desunión que se inicia en esos congresos Pan Americanos que no tienen otro fin que separar a los pueblos Latinoamericanos en sus marchas de simpatías hacia su antigua metrópolis, haciéndolos subordinados hoy del gran pueblo sajón americano fundado por Washington, para perder primero sus usos, religión y costumbre, luego la lengua de sus padres y después su libertad como ha sucedido a los pueblos hermanos de Cuba y Puerto Rico ${ }^{22}$.

En las memorias de la Asociación Patriótica Española de Buenos Aires que fueron publicadas por el diario se informó de la visita de sus directivos al Presidente argentino, además de las celebraciones y festividades. Luego de la guerra y la donación del crucero "Río de la Plata" a la armada española, la razón de ser en tiempos de paz de la institución,

\footnotetext{
22 “La Asociación Patriótica Española de Buenos Aires”, La Voz de España, 16/06/1901. P2.
} 
y de "todos los españoles", era "jurarse consagrar la vida al fin único de que no se pierda ni la religión ni la lengua de nuestros padres en el continente descubierto por Colón" ${ }^{23}$.

Una de las líneas editoriales de la prensa periódica española en América fue la defensa de España, ante lo que pudiera percibirse como un ataque o comentario denigratorio, tanto a la historia de la colonización como al presente político y social de la península. En este sentido, La Voz de España tampoco se apartó de este modelo de prensa y de periodismo. En general, también se percibió como un buen "entendido sentimiento patriótico" defender a España. Como vimos en párrafos anteriores, la custodia del honor de los "españoles" en América se manifestó tanto en la defensa a los miembros de la monarquía como a las costumbres del pueblo español. Esta postura la vemos en la columna "Hablar por no dejar", en donde el periódico chileno La Unión se mofaba de las prácticas culturales españolas.

A causa de "desórdenes" en la vía pública en una procesión que se realizó en España y sin nombrar la región, el diario chileno calificó como una "situación ridícula y penosa de España". Esta afirmación ameritó la respuesta de Cavestany en el periódico del 16 de junio, preguntándose "pero ¿a qué escandalizarse tanto y tratar de ridícula a una nación, porque un mal intencionado grita "al toro" y la comitiva de una procesión se disperse?" Para luego continuar: "¿Por qué el señor Ronquillo [Director del diario La Unión de Valparaíso] se ensaña tanto con la pobre España llamándola ridícula y otros excesos por causas tan baladíes?" Preguntándose, después, si no ocurren estas mismas cosas en Italia, Francia o los países americanos, por tener éstos también "¿los naturales efectos del ardor de sangre de la raza latina?"

La columna que comenzó como una defensa de España, pues "La voz de España no podía permanecer en un culpable silencio", culminó como un ataque a las costumbres americanas desde una posición de superioridad eurocéntrica. La evaluación negativa sobre las costumbres de la sociedad chilena se apoyó en una escala de valores que redujo a un nivel rudimentario la práctica del "tomar mate", a diferencia del café, el té o el brandy. Luego de calificar este artículo como "pelambre gratuita", Cavestany avanzó degradando las prácticas cotidianas de la sociedad local. Comenzó de la siguiente manera:

apuesto mi mano derecha (y conste que es con la que me santiguo) a que cuando se estaba escribiendo el artículo a que aludo, había en la pieza un gran caldero encendido en cuyo centro se asentaba majestuosamente una enorme tetera haciendo un poético arrullo clo clo clo; al alcance de la mano, un primoroso mate ofreciendo su sabroso contenido por el plateado tubo de una linda bombilla y el ambiente saturado de un agradable perfume de azúcar quemado. Díganme mis lectores si a la vista de este cuadro, no se sentiría con ganas de pelar al prójimo, el

23 “La Asociación Patriótica Española de Buenos Aires”, La Voz de España, 16/06/1901. P3. 
mismísimo ángel de la caridad. Y no a pelar sotto voce, sino a grito hendido, hasta quedarse ronco ${ }^{24}$.

Esta descripción encerró un contrato de lectura particular, un tono de complicidad para con el lector español que estaba habituado a "otras costumbres" claramente más europeizantes y por lo tanto, y con la escala de valores de la época, más civilizadas. Claramente Cavestany le habló a un grupo de lectores particulares, "españoles", miembros de la élite, con los que evidentemente buscó congraciarse. En parte podemos observarlo en la nota del 23 de junio de 1901 titulada "La colonia española en Valparaíso". En esta elogiosa columna, Cavestany felicitaba al "núcleo y centro de los caballeros que integran la colonia española" de Valparaíso por la constitución de lo que se entendía en la época como las asociaciones indispensables que un colectivo de inmigrantes debía poseer para convertirse en "colonia" 25.

Entre las instituciones constitutivas de un "lazo colonial y comunitario" se daba cuenta del Círculo Español, de la Asociación Española de Socorros Mutuos, así como también poseían un grupo de bomberos (queremos destacar que la colectividad española de Buenos Aires no poseía este cuerpo ya que lo proveía el Estado provincial) pues "no quisieron los españoles ser menos que otros europeos constituidos aquí en colonia". Además, se había creado a finales del siglo XIX el Banco Español - Italiano y sociedades de seguros. Para completar el círculo de una "comunidad española" en la sociedad de destino era necesario un periódico. Este espacio pretendía ser ocupado por La voz de España. Entre las tareas por continuar, el diario planteó la necesidad de construir una escuela y un hospital para las ciudades de Valparaíso y también para la capital chilena.

Estas instituciones funcionarían como un testimonio expreso no sólo de la presencia de los inmigrantes españoles, sino que señalaría otro aspecto muy importante en las valoraciones de la época. Por un lado la "prosperidad" y "riqueza" de un sector privilegiado de sus miembros y por el otro, la idea de una "dirección" de ese colectivo de inmigrantes que, lejos de permanecer "dispersos", constituían esta "sociabilidad" y "lazo social" tan declamado hacia la segunda mitad del siglo XIX. La columna "La colonia española de Valparaíso" realizó un repaso por aquellas instituciones y actores necesarios para constituir un colectivo organizado: asociaciones con diversos fines, una élite dirigencial y además: un periódico que funcione de nexo entre los individuos y las instituciones y que pueda defender las posiciones de su grupo en el "espacio público" del periodismo chileno ${ }^{26}$.

\footnotetext{
24 "Hablar por no dejar", La Voz de España, 16/06/1901. P2.

25 "La colonia española en Valparaíso", La Voz de España, 23/06/1901. P1

26 “La colonia española en Valparaíso”, La Voz de España, 23/06/1901. P1
} 
Tomando nuevamente el proyecto aludido de Telmo Arenas ${ }^{27}$ y Luis Moncayo encontramos también notas editoriales destinadas a reivindicar la presencia española en Chile, lo que a su vez abonó un proceso constitutivo para la identidad nacional española. La publicación España y Chile aportó elementos novedosos para la prensa de su época a partir de la incorporación de la caricatura. Esta práctica muy extendida en España cobró un impulso muy importante en la Argentina y México, pero estuvo algo relegada en las publicaciones chilenas.

En el primer número del 21 de mayo de 1886 el mensuario publicó un grabado alusivo a la figura de Arturo Prat junto a un poema escrito por Telmo Arena. Reivindicar la figura del oficial de la marina chilena muerto en combate naval durante la Guerra del Pacífico en el año 1879 nos pareció una decisión editorial que debía analizarse, sobre todo teniendo en cuenta cómo fue la historia reciente chilena en relación con España, cuya armada había bombardeado la Ciudad de Valparaíso en el conflicto de 1866.

Agustín Arturo Prat Chacón, quien fue considerado un héroe nacional luego de su muerte, nació en San Agustín de Puñal, Chillán, Chile, y sus padres Ignacio Prat Barril y María del Rosario Chacón también habían nacido en Chile. Sin embargo, su abuelo paterno, Ignacio Prat Guigueras era oriundo de Gerona, Cataluña, y emigró hacia América alrededor de año 1806.

El origen español del marino héroe fue el argumento principal para presentar en sociedad una publicación española en Chile. Dada la reinante hispanofobia luego del conflicto, muchos españoles debieron partir del territorio y muchos otros adoptar la ciudadanía chilena para poder permanecer en el país, por lo que entendemos la razón por la cual el primer periódico español en Santiago se publicara recién en el año 1878. En este sentido, la experiencia de España y Chile se constituyó sobre un escaso recorrido de la prensa española en el país. En el inicio de la publicación se colocaba lo siguiente:

pero no dejaremos de decir que el nombre de Arturo Prat evoca en la mente de los buenos españoles gratísimos recuerdos; pues no solo vemos en él un descendiente directo de nuestros bravos marinos, continuador en Chile de las glorias de Churruca y Gravina, sino el motivo que por una serie de extrañas circunstancias vino a reanudar en indisoluble lazo las relaciones amistosas que jamás debieron interrumpirse entre dos pueblos hermanos, cuyos hijos tienen el mismo origen, igual carácter, idénticas creencias, las mismas nobles aspiraciones y que todos expresan sus ideas en el armonioso y riquísimo idioma español. ${ }^{28}$

\footnotetext{
${ }^{27}$ Encontramos participaciones de Telmo Arenas en Revistas ilustradas de Madrid: Madrid Cómico, Director: Miguel Casañ, (1880 - 1923) y Día de Moda, Director: Eusebio Blasco (1881). Vistado el 10 de diciembre de 2018 en http://www.bibliotecavirtualmadrid.org/bvmadrid_publicacion/es/publicaciones/

28 "Nuestro grabado. Arturo Prat", España y Chile, 21/5/1886. P1.
} 
En el paralelismo propuesto, Prat fue una continuación histórica de Cosme Damián Churruca y Elorza y de Federico Carlos Gravina y Nápoli, ambos oficiales de la Marina Real española que murieron en la Batalla de Trafalgar de 1805. En sintonía con las corrientes ideológicas de fines de siglo XIX, las cualidades de Prat, arrojo, valentía y amor a la patria, fueron una herencia española que junto con el carácter y el idioma español, conformaron una comunidad que iba más allá de la coyuntura. Con esta lógica y a través de la figura de Arturo Prat, como un cruce de caminos entre España y Chile, se presentaba la hoja homónima en el seno de la prensa chilena.

En el segundo número de la publicación España y Chile se incluyó la columna "Vínculos nacionales", firmada por el escritor chileno filo hispanista Carlos Segundo Lathorp. Para el letrado chileno, la clave del vínculo pasa por la confraternización entre "hermanos" pues esto entraña la "fuerza moral y la respetabilidad de la familia" y los diferencia de la "vitalidad aislada y errante del salvaje". En sintonía con la recién creada Unión Iberoamericana y con la prédica del político y escritor español Rafael María de Labra, el esfuerzo debería ponerse en estrechar las relaciones a través de la cultura y la hegemonía cultural hispánica en las jóvenes repúblicas suramericanas, para posteriormente avanzar sobre convenios y acuerdos de preservación de derechos y también comerciales. Lathorp proponía que la ligazón a través del lenguaje era el puente más importante para lograr estos objetivos. Afirmaba que,

debemos celebrar con la madre patria tratados que uniformen nuestro lenguaje, haciendo obligatorio en Chile el estudio de la gramática española sobre todo en su parte ortográfica, tratados de propiedad literaria que concilien la justa garantía de los autores con la propagación recíproca de sus obras, tratados de títulos universitarios que permitan a los poseedores establecerse autorizadamente. ${ }^{29}$

En sintonía con debates precedentes que se llevaron adelante por la cuestión del idioma y la potestad española para "regularlo", la postura del articulista se ubicó entre quienes afirmaban que debía resguardarse sin modificaciones locales. En este sentido, para Lathorp "el idioma es la fotografía articulada de cada raza y su lazo más firme de familia, de sociedad y de nación" (Del Valle, Stheeman, 2004).

\section{Conclusiones}

Para dar un cierre transitorio a este trabajo, creemos que el estudio de las empresas periodísticas de los españoles en Chile es un área por explorar y que de allí podrían surgir nuevas preguntas para complementar los excelentes estudios que ya existen sobre la

29 “Vínculos nacionales”, España y Chile, 30/06/1886. P2 
inmigración española hacia el país. Avanzar en esta línea se presenta como un desafío intelectual que está llamado a dialogar con otras corrientes de la historiografía como la historia política, la historia de la prensa y la historia intelectual.

A partir del estudio de las publicaciones aquí reseñadas, podemos esbozar algunas conclusiones parciales. Una primera impresión nos indica la predominante vida efímera de las publicaciones españoles. Estas características de los periódicos del último cuarto del siglo XIX obedecían a factores múltiples. En principio por el limitado número de inmigrantes españoles en Chile, lo que disminuía drásticamente el potencial número de lectores de diarios. Además de este limitante, hemos observado cómo estos periódicos tenían que adaptarse al ambiente de opinión de la sociedad local. Como observamos para el caso de la publicación España y Chile, una ideología política que traspasaba los límites de los consensos básicos no tenía una buena recepción por parte de sus pares en la prensa. El emprendimiento de Luis Moncayo en 1886 sólo se extendió por cuatro números, sus innovaciones en la caricatura y las críticas a las políticas locales marcaron rápidamente los límites para este tipo de prensa, sobre todo cuando se trataba de inmigrantes. En este sentido, El Noticiero Español, de Rodríguez Menica, comenzó su publicación tres años después, y dado sus orientaciones políticas más conservadoras en sintonía con gran parte de la élite de la colonia española de Santiago, unido a su prescindencia de opinar sobre la política doméstica, recibió otro trato de la sociedad local y de los inmigrantes españoles.

La otra publicación analizada, La Voz de España, nos muestra también las limitaciones de emprender un periódico español en Chile inmediatamente iniciado el siglo XX. Cavestany intentó allí el establecimiento de una hoja española, aprovechando el vacío existente. Sin embargo, este emprendimiento resultó en un fracaso, como él mismo lo expresó en sus memorias (Cavestany, 1917: 101 - 102) Los insistentes pedidos del director de la hoja para lograr mayor número de suscriptores resultaron estériles para una colectividad porteña que, al parecer podía prescindir de un diario español. De la misma manera que su antecesor inmediato, La España, el periódico de Cavestany tampoco logró consolidarse.

El escaso número de españoles y una colectividad que disponía de un puñado de instituciones representativas, pero que carecía de otras de no menor importancia tales como un hospital o escuelas, estaba todavía en camino de una completa organización. Suponemos que, para la época analizada, la existencia de un solo periódico en Santiago, de aparición regular, alcanzó a cubrir las necesidades del colectivo español en las dos ciudades más importantes del país.

Desde el punto de vista del posicionamiento político, La Voz de España mantuvo un alineamiento al conservadurismo monástico encarnado en la figura de Silvela, y partidario de un progreso gradual de la sociedad. Su defensa de la identidad nacional española se hizo explícita en su apoyo a la monarquía, a quien interpretó como el 
máximo representante de la nacionalidad. Pueden observarse diferencias políticas muy importantes entre los periódicos de Cavestany y de Aparicio Sarabia con la hoja publicada en Santiago de Chile a cargo de Luis Moncayo. Los primeros realizaron una cerrada defensa de la nacionalidad española evitando las escisiones políticas domésticas, para representar una pretendida unidad del colectivo de inmigrantes sin fisuras. Aquí, la nación estuvo por delante de la política. En el caso de España y Chile, por el contrario, las diferencias se dejaron entrever desde el primer número y la identidad nacional genuina, estuvo reservada solamente para una facción de la sociedad española, aquella vinculada con la tradición republicana y federal, antimonárquica. Al posicionamiento político, también debía agregársele los tonos de la enunciación de los discursos políticos, poco comunes en el espacio público chileno. El lugar en donde todas estas publicaciones analizadas encontraron un lugar común fue en la defensa de la lengua castellana como un espacio para la vinculación entre España y América. A través de la defensa de la lengua, tema muy boga en el cambio de siglo, se buscaba mantener también la hegemonía cultural, ante el avance y la amenaza de la cultura norteamericana.

\section{Referencias bibliográficas}

CAVESTANY, GENARO (1917) Memorias de un sesentón sevillano, Sevilla, Imprenta de F. Díaz, Plaza de Alfonso XIII 6.

CENSO GENERAL de la República de Chile levantado en 1854, (1858) Santiago de Chile

DEL VALLE, José y STHEEMAN, Luis Gabriel (eds.) (2004) La batalla del idioma. La intelectualidad hispánica ante la lengua, Madrid, Vervuert Iberoamericana.

EDWARDS, Lisa (2018) “Intelectuales y pensamiento católico, siglos XIX y XX" en Jaksic, Iván y Gazmuri Stein, Susana (Eds.) Historia política de Chile, 1810 - 2010, Tomo IV Intelectuales y pensamiento político, Santiago de Chile, FCE / UAI.

ESTRADA TURRA, Baldomero (2012) Desarrollo empresarial urbano e inmigración europea: españoles en Valparaíso, 1880 - 1940, Memoria para optar al grado de Doctor, Universidad Complutense de Madrid, Madrid.

ESTRADA TURRA, Baldomero (2018) La azarosa y difícil aventura de migrar. Españoles en Chile (1880 - 1950), Santiago, Ril Editores

GAZMURI STEIN, Susana (2018) "Debates republicanos, liberales y conservadores durante el siglo XIX" en Jaksic, Iván y Gazmuri Stein, Susana (Eds.) Historia política 
de Chile, 1810 - 2010, Tomo IV Intelectuales y pensamiento político, Santiago de Chile, FCE / UAI

JAKSIC, Ivan (2018) "Disciplinas y temáticas de la intelectualidad chilena en el siglo XIX" en Jaksic, Iván y Gazmuri Stein, Susana (Eds.) Historia política de Chile, 1810 2010, Tomo IV Intelectuales y pensamiento político, Santiago de Chile, FCE / UAI

LORENZO, Santiago (2012) “Ambiente cultural de una ciudad mercantil, Valparaíso: 1830 - 1930" en Estrada Turra, Baldomero (comp.) Valparaíso. Progresos y conflictos de una ciudad puerto, 1830 - 1950, Santiago, RIL Editores

MONTEALEGRE, Jorge (2018) "Mujeres para la risa. La representación femenina en caricaturas del siglo XIX" en Tebeosfera (2016; ACYT) 3o época - 8. Visitado el $15 / 02 / 2019$

https://www.tebeosfera.com/documentos/mujeres_para_la_risa._representa cion_femenina en_caricaturas del_siglo_xix.html

RIVADULLA, Daniel; NAVARRO, Jesús Raúl y BERRUEZO (1992) María Teresa. El exilio español en América en el siglo XIX, Madrid, Editorial MAPFRE, S. A. 1992. Pp. 273 $-283$.

SANTA CRUZ, EDUARDO (2014) "Prensa y sociedad en Chile en los comienzos republicanos: El Araucano como modelo de prensa" en Estudios sobre el Mensaje Periodístico. Vol. 20, Núm. 1 (enero - junio) Madrid, Servicio de Publicaciones de la Universidad Complutense.

SANTA CRUZ, Eduardo (2011) "Prensa y modernización en América Latina y Chile en la segunda mitad del siglo XIX: la crónica y los cronistas" en Estudios sobre el mensaje periodístico. Vol. 17, núm. 2, Madrid, Servicio de Publicaciones de la Universidad Complutense. 